\title{
Related factors and use of free preventive health services among adults with intellectual disabilities in Taiwan
}

Suh-May Yen ${ }^{1,2}$, Pei-Tseng Kung ${ }^{3+}$, Li-Ting Chiu ${ }^{1}$ and Wen-Chen Tsai ${ }^{1{ }^{*}+}$

\begin{abstract}
Background: This study aimed to investigate the utilization of preventive health services in the adults with intellectual disabilities from the nationwide database.

Methods: The research method of this study is secondary data analysis. The data was obtained from three nationwide databases from 2006 to 2008. This study employed descriptive statistics to analyze the use and rate of preventive health services by intellectual disabled adults. Chi-square test was used to determine the relationship between the utilization of preventive health services and these variables. Multivariate logistic regression analysis was used to explore the factors that affect intellectual disabled adults' use of preventive health services.

Results: Our findings indicated $16.65 \%$ of people with intellectual disabilities aged over 40 years used the preventive health services. Females were more frequent users than males $(18.27 \%$ vs. $15.21 \%, p<0.001)$. The utilization rate decreased with increasing severity of intellectual disabilities. The utilization was lowest (13.83\%) for those with very severe disability, whereas that was the highest (19.38\%) for those with mild severity. The factors significantly influencing utilization of the services included gender, age, and marital status, urbanization of resident areas, monthly payroll, low-income household status, catastrophic illnesses status and relevant chronic diseases and severity of disability.

Conclusions: Although Taiwan's Health Promotion Administration (HPA) has provided free preventive health services for more than 15 years, people with intellectual disabilities using preventive health care tend to be low. Demographics, economic conditions, health status, relevant chronic diseases, environmental factor, and severity of disability are the main factors influencing the use of preventive healthcare. According to the present findings, it is recommended that the government should increase the reimbursement of the medical staff performing health examinations for the persons with intellectual disabilities. It is also suggested to conduct media publicity and education to the public and the nursing facilities for the utilization of adult preventive health services.
\end{abstract}

Keywords: Intellectual disabilities, Disability, Preventive health service, Adult health examination

\section{Background}

The global prevalence of intellectual disabilities was 10.37 per 1,000 populations [1]. In the end of 2011, there were 98,046 people with intellectual disabilities, accounting for $0.4 \%$ of the total population in Taiwan [2]. According to a survey conducted in 2006, $89.5 \%$ of people with intellectual disabilities in Taiwan lived with family members

\footnotetext{
*Correspondence: wtsai@mail.cmu.edu.tw

tEqual contributors

'Department of Health Services Administration, China Medical University, No. 91 Hsueh-Shih Road, Taichung 40402, Taiwan

Full list of author information is available at the end of the article
}

and $78.0 \%$ had no paid employment [3]. People with intellectual disabilities had a shorter life expectancy than did the general population $[4,5]$. Standardized mortality ratios for adults with moderate or severe intellectual disabilities were 3 times higher than those for the general population [6].

A study in the Netherlands determined that people with intellectual disabilities had 2.5 times more health problems than did those without intellectual disabilities [7]. Numerous people with intellectual disabilities developed neurological, digestive, dermatological, and mental 
disorders, as well as obesity, diabetes, and cardiovascular disease [8-11]. People with intellectual disabilities might be unaware of physical problems and might have difficulty verbally expressing such conditions. Patients with intellectual disabilities are often rushed to hospitals for treatment when their physical conditions become severe. Therefore, people with intellectual disabilities must expend more time and effort in receiving medical care and may not be able to obtain required appropriate treatments [12-14].

Previous studies have demonstrated that the intellectually disabled persons were less likely to receive preventive health services than the others [15-18]. For instance, only $25 \%$ of women with learning disabilities in Exeter (a city in southwestern England) underwent cervical screening [19], and in Wales, only $31 \%-41 \%$ of people with learning disabilities received annual health assessments in 2006 and 2009 [20]. People with intellectual disabilities have substantial health needs, and have been reported to benefit from regular health assessments. A randomized controlled study conducted in Australia showed that people with intellectual disabilities who regularly received health assessments were newly diagnosed with diseases at a rate that was 1.6 times that of those who did not receive regular health assessments [21].

A study in the United States suggested that an increase in preventive services could avert the loss of more than 2 million life-years annually [22]. Increasing clinical preventive health services could effectively lower subsequent medical expenses [23-26]. Previous studies have indicated that sex, marital status [27], educational level, age, income, health status, severity of disability, and urbanization level influence the use of preventive health services among disabled people [28].

To reduce exorbitant medical expenses and improve unequal access to health care, free preventive health services for adults have been promoted since 1995 in Taiwan. The services include medical examinations, health education, blood, and urine tests. All adults aged over 40 years are accessible to this free service. Frequency limitations of this service varied according to different age ranges, i.e., once per three years for the persons aged 40-64 years and once per year for those who aged over 65 years. The examination outcomes are reported to patients, and primary care physicians suggest necessary additional diagnoses, treatments, or follow-ups. There were 21,042 adults with intellectual disabilities met the requirements in 2008. The purpose of this study was to explore of preventive health service utilization among these people and the factors associated with their use.

\section{Methods}

\section{Data source and participants}

According to the Disabled Welfare Law (1980), local governments in Taiwan provide support such as social welfare, special education, and health care to people with intellectual disabilities. Intelligence quotient (IQ) scores are diagnosed based on an official test administered by a psychologist and certified by the government; the scores are then confirmed by a doctor accredited by the government. If the IQ score of a person is below 70 (more than 2 standard deviations below the mean), the person is identified as having intellectual disabilities. Local governments certify disabled residents and report cases to the central government, and the Ministry of the Interior maintains a registry of certified cases. Intellectual disabilities are categorized according to four levels of severity, namely very severe (IQ: 5 standard deviations below the mean), severe (IQ: 4-5 standard deviations below the mean), moderate (IQ: 3-4 standard deviations below the mean), and mild (IQ: 2-3 standard deviations below the mean).

The study population was 21,042 people in Taiwan with intellectual disabilities, aged over 40 years, and registered with the Ministry of the Interior as of 2008 (Department of Statistics, 2008). Among them, 17.46\%, $32.20 \%, 30.34 \%$, and $20.00 \%$ were diagnosed with mild, moderate, severe, and very severe levels of intellectual disabilities, respectively.

The Health Promotion Administration (HPA) has provided free preventive health services for adults in Taiwan since 1995 and maintains a dataset of records of adults who have used such services. Since 1995, Taiwan has implemented the National Health Insurance (NHI) program; $99.68 \%$ of the residents are enrolled in the NHI program. The NHI program is a universal, comprehensive health insurance program with a considerably low copayment. The NHI Administration holds all medical claims data and publishes the National Health Insurance Research Dataset for academic research annually. In this study, three data sources were used: the 2006-2008 preventive health service dataset obtained from the HPA, medical claims data from the NHI Research Database provided by the Ministry of Health and Welfare, and information on disabled people from the 2008 Registry of Disabled People obtained from the Ministry of the Interior. The Statistics Center of the Department of Health, Taiwan, helped match the three datasets with personal identification numbers and provided a dataset that included that necessary information for this study. All personal identification information was deleted and personal privacy was protected. The institutional review board of China Medical University and Hospital approved this study (IRB No. CMU-REC-101-012).

\section{Description of variables}

Variables in this study included demographics (e.g., gender, age, marital status, educational level, and aborigine status, economic conditions (e.g., premium-based monthly payroll, low-income household status), health status (with 
or without a catastrophic illness/injury), chronic diseases (including mental disorders, musculoskeletal system and connective tissue diseases, neurological disorders, cancers, blood and blood-forming organs diseases, circulatory system diseases, respiratory diseases, endocrine and metabolic diseases, digestive diseases, genitourinary system diseases, skin and subcutaneous tissue disease, diseases of eyes and auxiliary organs, ear and mastoid diseases, infectious diseases, and congenital malformations); environmental factors (i.e., urbanization of resident areas), severity of disability (i.e., very severe, severe, moderate, and mild), and utilization of adult preventive health services. Urbanization was categorized into eight levels. The first level was the area with the highest level of urbanization, whereas the eighth level was the region with the lowest level of urbanization. A low-income household was defined as a household in which the average monthly income per person was below the lowest living index, i.e., $60 \%$ of the living expenditure per person in the previous year in the local area of the household [29].

\section{Statistical analysis}

A statistics software package (SAS 9.2) was used for data analysis. Descriptive statistics was used to describe the percentages of demographic characteristics, economic status, health status, environmental factors, levels of intellectual disability, and the utilization of preventive health services for adults. Chi-square test was used to determine the relationship between the utilization of preventive health services and these variables. Multivariate logistic regression analysis was applied to explore the factors associated with the use of adult preventive health services among the persons with intellectual disabilities. The full model approach was applied in logistic regression analysis. In this study, a $p$ value of less than 0.05 was considered statistically significant.

\section{Results}

\section{Basic characteristics of the participants}

Among the 21,042 participants, males were the majority $(52.97 \%, \mathrm{n}=11,145)$ (Table 1$)$. Those aged 45-49 years were predominant $(26.66 \%, \mathrm{n}=5,609)$. Most of the participants had a educational level of elementary school or lower $(72.84 \%, \mathrm{n}=15,327)$. Those with premium-based monthly payroll less than NT $\$ 15,840$ (New Taiwan Dollars, NT\$) (U.S. \$1=NT \$30) accounted for the majority (51.69\%, $\mathrm{n}=10,877$ ). Regarding the relevant chronic diseases, intellectual disability with comorbid mental illness (26.44\%) and circulatory system disease (23.93\%) were ranked in the first and second places, respectively. Those with moderate level of severity of intellectual disabilities were predominant, accounting for $32.20 \%(\mathrm{n}=6,775)$.
The utilization of adult preventive health services among the participants

As presented in Table 1, 16.65\% ( $n=3,503)$ of participants aged over 40 years used the adult preventive health services. Of them, more females (18.27\%) used the services than males $(15.21 \%, p<0.001)$. Those aged 60-64 years had the highest utilization $(20.20 \%, p<$ 0.001). According to the levels of urbanization, those living in the areas of $6^{\text {th }}$ level of urbanization had the highest utilization (19.59\%) whereas those living in urbanization of first level (most urban) had the lowest utilization $(11.15 \%)(p<0.001)$. The participants with any catastrophic illness/injury used more preventive health services than those without $(23.72 \%$ vs. $15.68 \%, p<0.001)$. Among those with relevant comorbid diseases, those having the highest utilization rate were those with diseases of the ear and mastoid process (31.56\%), followed by those with endocrine and metabolic disease (30.66\%), and those with cancers had the lowest utilization rate $(18.80 \%)$ compared to the others. The persons with more severe level of intellectual disability were the lower frequent users of services $(p<0.001)$, indicating that the lowest users were those with very severe level $(13.83 \%)$ and those with highest utilization rate were the subgroup of mild level of disabilities (19.38\%).

\section{Factors influencing the utilization of adult preventive health services among participants}

The results of analyzing variables associated with the utilization of adult preventive health services are shown in Table 2 . The factors significantly influencing the utilization included gender, age, marital status, urbanization of resident area, premium-based monthly payroll, low-income household status, catastrophic illness/injury status, relevant chronic diseases, and severity of intellectual disabilities. After controlling for other variables, males were 0.87 times less likely to use adult preventive health services than females $(\mathrm{OR}=0.87,95 \% \mathrm{CI}=0.80-0.95)$. When those aged 40-44 years were used as a reference group, the groups aged 65-69 years or $\geq 70$ years had significantly lower probabilities to use the services $(\mathrm{OR}=0.35$, 95\% CI $=0.28-0.44$; OR $=0.33,95 \% \mathrm{CI}=0.26-0.42$ ). Furthermore, the probability of using the services increased with decreasing urbanization of resident areas. Those living in areas with the $6^{\text {th }}$ level of urbanization were 2.47 times more likely to use the services than those living in the area of first level (most urban) $(\mathrm{OR}=2.47,95 \% \mathrm{CI}=$ 2.06-2.97).

Using those with less than NT\$15,840 of premiumbased monthly payroll as a reference group, the group with NT\$16,500-22,800 was more likely to use the adult preventive health services $(\mathrm{OR}=1.16,95 \% \mathrm{CI}=1.04-1.29)$. Those with low-income household status were more likely to use services than those without low-income household 
Table 1 Use of adult preventive health services among the intellectual disability: basic characteristics and bivariate analysis

\begin{tabular}{|c|c|c|c|c|c|c|c|}
\hline \multirow[b]{2}{*}{ Variables } & \multirow[b]{2}{*}{$N=21042$} & \multirow[b]{2}{*}{$\%$} & \multicolumn{2}{|c|}{ Used } & \multicolumn{2}{|c|}{ Did not use } & \multirow{2}{*}{$\begin{array}{c}x^{2} \\
p \text {-value }\end{array}$} \\
\hline & & & $n_{1}=3503$ & $\%$ & $\mathrm{n}_{2}=17539$ & $\%$ & \\
\hline Overall rate of use & & & & 16.65 & & & \\
\hline Gender & & & & & & & $<.001$ \\
\hline Female & 9897 & 47.03 & 1808 & 18.27 & 8089 & 81.73 & \\
\hline Male & 11145 & 52.97 & 1695 & 15.21 & 9450 & 84.79 & \\
\hline Age & & & & & & & $<.001$ \\
\hline 40-44 years & 3753 & 17.84 & 628 & 16.73 & 3125 & 83.27 & \\
\hline $45-49$ years & 5609 & 26.66 & 921 & 16.42 & 4688 & 83.58 & \\
\hline 50-54 years & 4420 & 21.01 & 774 & 17.51 & 3646 & 82.49 & \\
\hline $55-59$ years & 3089 & 14.68 & 609 & 19.72 & 2480 & 80.28 & \\
\hline $60-64$ years & 1817 & 8.64 & 367 & 20.20 & 1450 & 79.80 & \\
\hline $65-69$ years & 1028 & 4.89 & 94 & 9.14 & 934 & 90.86 & \\
\hline$\geq 70$ years & 1326 & 6.30 & 110 & 8.30 & 1216 & 91.70 & \\
\hline Educational level & & & & & & & 0.535 \\
\hline Elementary school and under & 15327 & 72.84 & 2566 & 16.74 & 12761 & 83.26 & \\
\hline Junior high school & 2645 & 12.57 & 454 & 17.16 & 2191 & 82.84 & \\
\hline Senior (vocational) high school & 550 & 2.61 & 80 & 14.55 & 470 & 85.45 & \\
\hline Junior college and university or above & 99 & 0.47 & 16 & 16.16 & 83 & 83.84 & \\
\hline Unclear & 2421 & 11.51 & 387 & 15.99 & 2034 & 84.01 & \\
\hline Marital status & & & & & & & $<.001$ \\
\hline Married & 6386 & 30.35 & 1239 & 19.40 & 5147 & 80.60 & \\
\hline Unmarried & 8463 & 40.22 & 1346 & 15.90 & 7117 & 84.10 & \\
\hline Divorced or widowed & 677 & 3.22 & 139 & 20.53 & 538 & 79.47 & \\
\hline Unclear & 5516 & 26.21 & 779 & 14.12 & 4737 & 85.88 & \\
\hline Level of urbanization ${ }^{a}$ & & & & & & & $<.001$ \\
\hline Level one & 1802 & 8.56 & 201 & 11.15 & 1601 & 88.85 & \\
\hline Level two & 3394 & 16.13 & 553 & 16.29 & 2841 & 83.71 & \\
\hline Level three & 2865 & 13.62 & 468 & 16.34 & 2397 & 83.66 & \\
\hline Level four & 1809 & 8.60 & 295 & 16.31 & 1514 & 83.69 & \\
\hline Level five & 3483 & 16.55 & 562 & 16.14 & 2921 & 83.86 & \\
\hline Level six & 3006 & 14.29 & 589 & 19.59 & 2417 & 80.41 & \\
\hline Level seven & 3173 & 15.08 & 569 & 17.93 & 2604 & 82.07 & \\
\hline Level eight & 1510 & 7.18 & 266 & 17.62 & 1244 & 82.38 & \\
\hline Premium-based monthly payroll & & & & & & & $<.001$ \\
\hline Dependents & 5303 & 25.20 & 720 & 13.58 & 4583 & 86.42 & \\
\hline$<15,840$ & 10877 & 51.69 & 1898 & 17.45 & 8979 & 82.55 & \\
\hline $16,500-22,800$ & 4143 & 19.69 & 770 & 18.59 & 3373 & 81.41 & \\
\hline $24,000-28,800$ & 358 & 1.70 & 57 & 15.92 & 301 & 84.08 & \\
\hline $30,300-36,300$ & 210 & 1.00 & 31 & 14.76 & 179 & 85.24 & \\
\hline$>38,200$ & 151 & 0.72 & 27 & 17.88 & 124 & 82.12 & \\
\hline
\end{tabular}


Table 1 Use of adult preventive health services among the intellectual disability: basic characteristics and bivariate analysis (Continued)

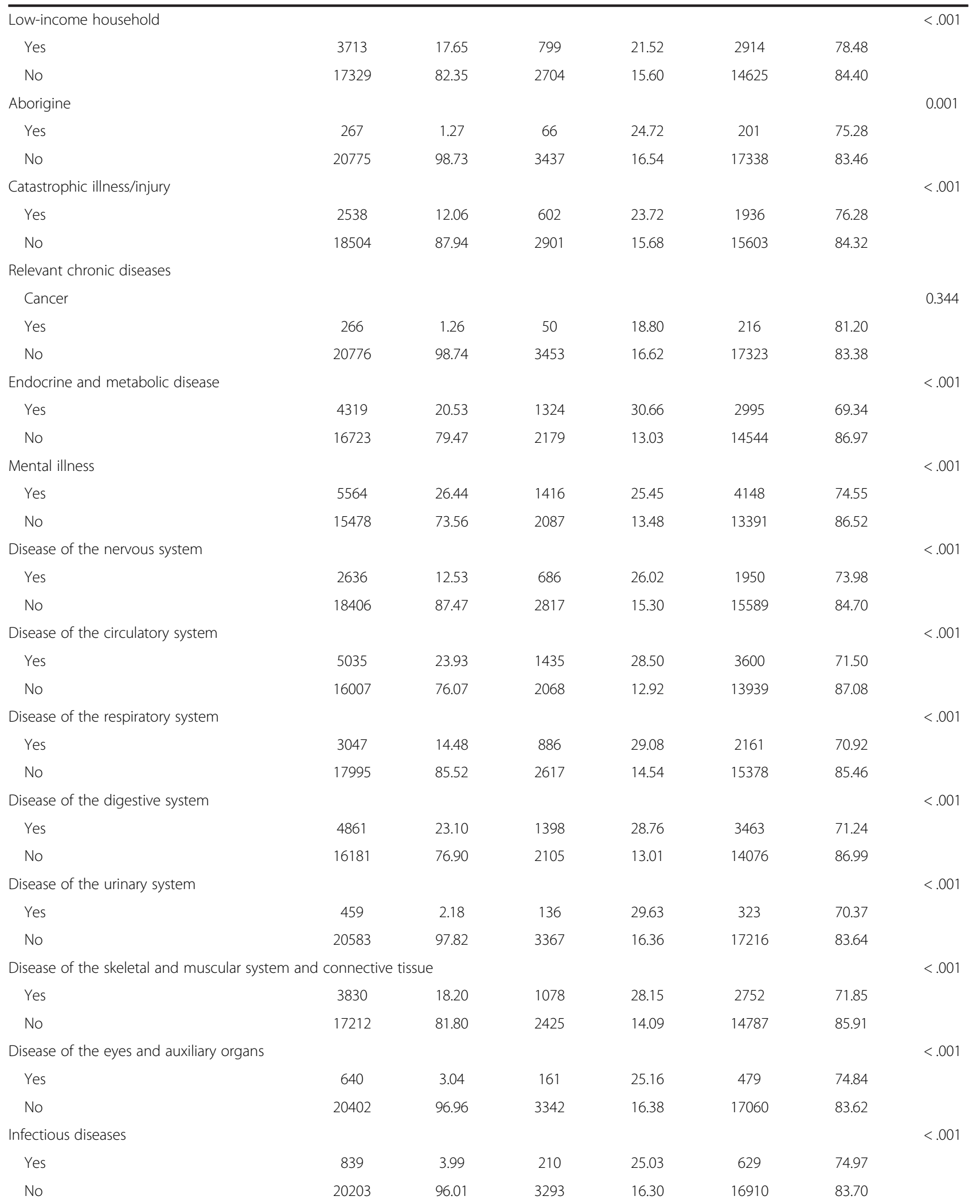




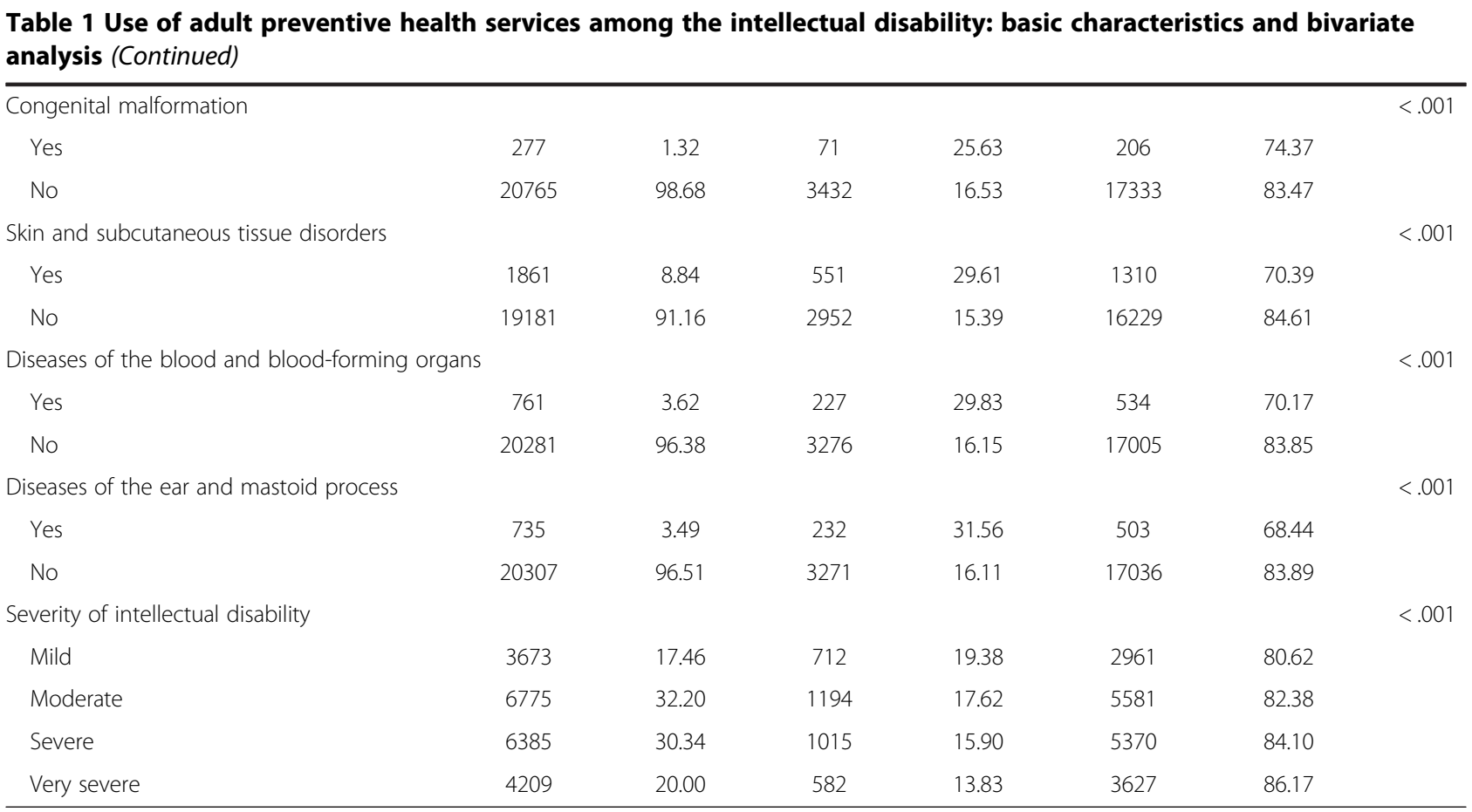

aevel one: the most urbanized areas.

status $(\mathrm{OR}=1.27,95 \% \mathrm{CI}=1.14-1.42)$. Those with catastrophic illness/injury were 1.22 times (95\% CI $=1.08$ 1.38) more likely to use the services than those without. In addition, those having endocrine and metabolic diseases $(\mathrm{OR}=1.79,95 \% \mathrm{CI}=1.63-1.96)$ or circulatory system diseases $(\mathrm{OR}=1.57,95 \% \mathrm{CI}=1.43-1.72)$ were more likely to use the services than those who had not. The probability of using the services decreased with increasing severity of intellectual disabilities. Those with very severe intellectual disability were 0.75 times less likely to use the services than those with mild level of severity (95\% CI $=0.66-0.86)$.

\section{Discussion}

In 2004, the overall rate of use of adult preventive health services among those aged 40 to 64 years was $42 \%$, while the rate of use among those aged 65 years or older was $38 \%$ [27]. However, only $16.65 \%$ of people with intellectual disabilities aged over 40 years used the preventive health services in the years 2006-2008, which was much lower than that of the general population. Another study indicated that, in Taiwan, among the disabled people using adult preventive health services, people suffering from chronic epilepsy had the highest use rate (23.33\%), whereas disabled people with major organ malfunction had the lowest use rate (10.21\%) [27].

The results of this study indicated that the utilization of adult preventive health services were not significantly associated with aborigine status and educational level. The finding of females with higher probability to use the services than males was consistent with previous studies reporting the utilization of relevant preventive health services [30-32]. Those aged $\geq 65$ years were less likely to use the services than the others, which might be associated with many elderly persons with intellectual disabilities living in psychiatric hospitals, nursing facilities, and nursing homes [33].

People with an "unclear" marital status exhibited the lowest use rate. Most people with this status may have been unmarried, and unmarried people exhibited the lowest use rate compared with other marital status groups. The probability of using preventive health services increased with decreasing urbanization of resident areas. Generally, people living in urban areas have more convenient transportations and can get faster access to medical resources than those living in rural areas. However, the Bureau of National Health Insurance (NHI) initiated an Integrated Delivery System program in 1999 that covered all 48 mountainous and island districts. Under the program, NHI-contracted hospitals are responsible for providing medical care, including outpatient care, emergency services, and specialty services. Health care, which consists of outpatient care, preventive care, disease screening, and health education, is provided from mobile vehicles. The mobile care services were provided in mountain areas and offshore islands to narrow the health care disparities. For those with intellectual disabilities living in rural areas, it was common that they and their families went together to receive preventive health services when the mobile care services were provided. As the result, a higher probability of using the services was observed for 
Table 2 Factors influencing the intellectual disability to use adult preventive health services: logistic regression analysis

\begin{tabular}{|c|c|c|c|c|c|c|c|c|}
\hline \multirow[b]{2}{*}{ Variable name } & \multicolumn{4}{|c|}{ Unadjusted } & \multicolumn{4}{|c|}{ Adjusted } \\
\hline & OR & & & p-value & OR & & & $p$-value \\
\hline \multicolumn{9}{|l|}{ Gender } \\
\hline Female & - & - & - & - & - & - & - & - \\
\hline Male & 0.80 & 0.75 & 0.86 & $<.001^{*}$ & 0.87 & 0.80 & 0.95 & $0.001^{*}$ \\
\hline \multicolumn{9}{|l|}{ Age } \\
\hline 40-44 years & - & - & - & - & - & - & - & - \\
\hline $45-49$ years & 0.98 & 0.88 & 1.09 & 0.689 & 0.92 & 0.82 & 1.03 & 0.140 \\
\hline 50-54years & 1.06 & 0.94 & 1.19 & 0.353 & 0.94 & 0.83 & 1.06 & 0.290 \\
\hline $55-59$ years & 1.22 & 1.08 & 1.38 & $0.001^{*}$ & 1.00 & 0.88 & 1.15 & 0.950 \\
\hline 60-64 years & 1.26 & 1.09 & 1.45 & $0.002^{*}$ & 1.03 & 0.89 & 1.21 & 0.677 \\
\hline $65-69$ years & 0.50 & 0.40 & 0.63 & $<.001^{*}$ & 0.33 & 0.26 & 0.42 & $<.001^{*}$ \\
\hline$\geq 70$ years & 0.45 & 0.36 & 0.56 & $<.001^{*}$ & 0.35 & 0.28 & 0.44 & $<.001^{*}$ \\
\hline
\end{tabular}

Educational level

Elementary school and under

Junior high school

Senior (vocational) high school

Junior college and university or above

0.591

1.03

0.91

1.16

0.676

$\begin{array}{lll}0.85 & 0.67 \quad 1.08\end{array}$

0.175

0.78

0.60

1.01

0.057

Unclear

0.96

0.878

1.11

0.63

1.96

0.714

$\begin{array}{lll}0.95 & 0.84 & 1.06\end{array}$

0.353

0.98

0.87

1.12

0.790

Marital status

Married

Unmarried

Divorced or widowed

$1.27 \quad 1.17$

1.39

$<.001 *$

1.07

0.97

1.19

0.168

$\begin{array}{lll}1.37 & 1.12 & 1.66\end{array}$

$0.002^{*}$

1.16

0.94

1.43

0.179

Unclear

$0.87 \quad 0.79$

0.96

$0.004^{*}$

0.79

0.71

0.88

$<.001^{*}$

Level of urbanization ${ }^{\text {a }}$

Level one
Level two
Level three
Level four
Level five
Level six
Level seven
Level eight
Premium-based monthly payr
$<15,840$
Dependent population
16,500-22,800
24,000-28,800
30,300-36,300
> 38,200

$\begin{array}{llllllll}1.55 & 1.31 & 1.84 & <.001^{*} & 1.79 & 1.49 & 2.15 & <.001^{*} \\ 1.56 & 1.30 & 1.86 & <.001^{*} & 1.85 & 1.53 & 2.23 & <.001^{*} \\ 1.55 & 1.28 & 1.88 & <.001^{*} & 1.90 & 1.55 & 2.33 & <.001^{*} \\ 1.53 & 1.29 & 1.82 & <.001^{*} & 1.91 & 1.59 & 2.29 & <.001^{*} \\ 1.94 & 1.63 & 2.31 & <.001^{*} & 2.47 & 2.06 & 2.97 & <.001^{*} \\ 1.74 & 1.47 & 2.07 & <.001^{*} & 2.19 & 1.82 & 2.64 & <.001^{*} \\ 1.70 & 1.40 & 2.08 & <.001^{*} & 2.08 & 1.68 & 2.57 & <.001^{*}\end{array}$

Low-income household

No

Yes

$\begin{array}{llllllll}0.74 & 0.68 & 0.82 & <.001^{*} & 0.90 & 0.81 & 1.01 & 0.061 \\ 1.08 & 0.98 & 1.19 & 0.104 & 1.16 & 1.04 & 1.29 & 0.011^{*} \\ 0.90 & 0.67 & 1.19 & 0.453 & 1.03 & 0.76 & 1.40 & 0.836 \\ 0.82 & 0.56 & 1.20 & 0.310 & 0.91 & 0.61 & 1.37 & 0.653 \\ 1.03 & 0.68 & 1.57 & 0.890 & 1.12 & 0.72 & 1.74 & 0.631\end{array}$

$\begin{array}{lllllll}1.48 & 1.36 & 1.62 & <.001^{*} & 1.27 & 1.14 & 1.42\end{array}$




\begin{tabular}{|c|c|c|c|c|c|c|c|c|}
\hline \multicolumn{9}{|l|}{ Aborigine } \\
\hline No & - & - & - & - & - & - & - & - \\
\hline Yes & 1.66 & 1.25 & 2.19 & $0.000^{*}$ & 1.29 & 0.95 & 1.75 & 0.103 \\
\hline \multicolumn{9}{|l|}{ Catastrophic illness/injury } \\
\hline No & - & - & - & - & - & - & - & - \\
\hline Yes & 1.67 & 1.51 & 1.85 & $<.001^{*}$ & 1.22 & 1.08 & 1.38 & $0.002^{*}$ \\
\hline \multicolumn{9}{|l|}{ Relevant chronic diseases } \\
\hline Cancer & 1.16 & 0.85 & 1.58 & 0.344 & 0.77 & 0.55 & 1.08 & 0.135 \\
\hline Endocrine and metabolic disease & 2.95 & 2.73 & 3.19 & $<.001^{*}$ & 1.79 & 1.63 & 1.96 & $<.001^{*}$ \\
\hline Mental illness & 2.19 & 2.03 & 2.36 & $<.001^{*}$ & 1.33 & 1.21 & 1.46 & $<.001^{*}$ \\
\hline Disease of the nervous system & 1.95 & 1.77 & 2.14 & $<.001^{*}$ & 1.11 & 0.99 & 1.24 & 0.067 \\
\hline Disease of the circulatory system & 2.69 & 2.49 & 2.90 & $<.001^{*}$ & 1.57 & 1.43 & 1.72 & $<.001^{*}$ \\
\hline Disease of the respiratory system & 2.41 & 2.21 & 2.63 & $<.001^{*}$ & 1.38 & 1.24 & 1.53 & $<.001^{*}$ \\
\hline Disease of the digestive system & 2.70 & 2.50 & 2.92 & $<.001^{*}$ & 1.49 & 1.36 & 1.63 & $<.001^{*}$ \\
\hline Disease of the urinary system & 2.15 & 1.76 & 2.64 & $<.001^{*}$ & 0.97 & 0.77 & 1.21 & 0.766 \\
\hline $\begin{array}{l}\text { Disease of the skeletal and muscularsystem and } \\
\text { connective tissue }\end{array}$ & 2.39 & 2.20 & 2.59 & $<.001^{*}$ & 1.31 & 1.19 & 1.45 & $<.001^{*}$ \\
\hline Disease of the eyes and auxiliary organs & 1.72 & 1.43 & 2.06 & $<.001^{*}$ & 0.94 & 0.77 & 1.15 & 0.549 \\
\hline Infectious diseases & 1.71 & 1.46 & 2.01 & $<.001^{*}$ & 0.98 & 0.82 & 1.16 & 0.776 \\
\hline Congenital malformation & 1.74 & 1.33 & 2.29 & $<.001^{*}$ & 1.05 & 0.78 & 1.41 & 0.748 \\
\hline Skin and subcutaneous tissue disorders & 2.31 & 2.08 & 2.57 & $<.001^{*}$ & 1.29 & 1.14 & 1.46 & $<.001^{*}$ \\
\hline Diseases of the blood and blood-forming organs & 2.21 & 1.88 & 2.59 & $<.001^{*}$ & 1.18 & 0.99 & 1.40 & 0.065 \\
\hline Diseases of the ear and mastoid process & 2.40 & 2.05 & 2.82 & $<.001^{*}$ & 1.08 & 0.91 & 1.29 & 0.382 \\
\hline \multicolumn{9}{|l|}{ Severity of intellectual disability } \\
\hline Mild & - & - & - & - & - & - & - & - \\
\hline Moderate & 0.89 & 0.80 & 0.99 & $0.026^{*}$ & 0.88 & 0.79 & 0.98 & $0.020^{*}$ \\
\hline Severe & 0.79 & 0.71 & 0.87 & $<.001^{*}$ & 0.82 & 0.73 & 0.92 & $0.001^{*}$ \\
\hline Very severe & 0.67 & 0.59 & 0.75 & $<.001^{*}$ & 0.75 & 0.66 & 0.86 & $<.001^{*}$ \\
\hline
\end{tabular}

a Level one: the most urbanized areas.

${ }^{*} \mathrm{p}<0.05$.

the persons with intellectual disabilities living in rural areas than those in urban areas. The probability of using preventive health services was found lower for the participants living in the most urbanized areas in this study. It was more likely due to better medical resources and higher accessibility in urban areas. They could obtain necessary medical treatments once they were ill. The high accessibility resulted in less attention being paid to use preventive health services by the participants living in urbanized areas.

Our results indicated that those with a low-income household status were more likely to use the services than the others, which was inconsistent with previous studies reporting that higher incomes were associated with more frequent use of preventive health services [34-36]. This finding may be resulted from the improvement in eliminating health inequalities between rich and poor populations, as a consequence of implementation of the NHI in Taiwan since 1995.

Aboriginal persons with intellectual disabilities had similar probability of using the services compared to non-aborigines. The results reflected the outcomes of efforts to improve health for vulnerable populations, and to eliminate gaps of health care for the minority in Taiwan. The probability of using the services was higher in those with any catastrophic illness/injury than those without. It was possible that their families were more concerned with changes in their health status for those participants with a catastrophic disease. Therefore, they paid more attentions and used more preventive health services. In consistent with previous studies [37], we also found that those with very severe level of intellectual disability used less preventive health services. The cognitive and language skills for the persons with very severe 
intellectual disabilities are lower compared with those with moderate and mild levels of severity. They need assistance and company of other people, which lead to more difficulties in using preventive health services.

This study was limited by the sources of data, which did not include information pertaining to personal health beliefs or health behaviors. The lack of objective information on household income in our dataset is regarded as a limitation of this study.

Although health policy has established strategies for eliminating health inequalities that affect people with intellectual disabilities in Taiwan, preventive health services must be markedly improved for people with intellectual disabilities. According to the findings, conducting publicity through the media and educating the public on using adult preventive health services are suggested. In addition, health care organizations should aggressively encourage and arrange free preventive health services for people with intellectual disabilities when they visit physicians, particularly for groups that were determined not to use such services.

\section{Conclusions}

This study demonstrated that the significant factors influencing the utilization of adult preventive health services for the persons with intellectual disabilities included gender, age, and urbanization of resident areas, premiumbased payroll, low-income household status, marital status, catastrophic illness/injury status, relevant chronic diseases, and severity of intellectual disabilities. Non-significant factors were aboriginal status and educational level. Those with lower use of preventive health services were characterized by male gender, aged $\geq 65$ years, high school education, unmarried, living in urban areas, with skin and blood-forming organs diseases, and with very severe intellectual disabilities.

\section{Abbreviations}

Cl: Confidence interval; HPA: Health Promotion Administration;

IQ: Intelligence quotient; NHI: National Health Insurance; NT\$: New Taiwan Dollar; OR: Odds Ratio; SAS: Statistics Analysis System.

\section{Competing interests}

The authors declare that they have no competing interests.

\section{Authors' contributions}

WCT and PTK conducted the study design. SMY and LTC drafted the manuscript. PTK and SMY conducted the statistical analysis. WCT was the supervisor of the study and revised the manuscript critically for important intellectual content. All authors read and approved the manuscript.

\section{Acknowledgements}

This study was supported by the grant (CMU99-S-47) from China Medical University and the grant (No.9805006A) from the Health Promotion Administration. The preventive health care files were obtained from the Health Promotion Administration, Ministry of Health and Welfare in Taiwan. We are also grateful for use of the National Health Insurance Research Database provided by the Ministry of Health and Welfare, Taiwan. The interpretations and conclusions contained herein do not represent those of the Health Promotion Administration in Taiwan. We would like to thank two reviewers and the editor for their valued comments.

\section{Author details}

'Department of Health Services Administration, China Medical University, No. 91 Hsueh-Shih Road, Taichung 40402, Taiwan. ${ }^{2}$ Department of Chinese Medicine, Nantou Hospital, Nantou, Taiwan. ${ }^{3}$ Department of Healthcare Administration, Asia University, Taichung, Taiwan.

Received: 25 October 2013 Accepted: 9 June 2014

Published: 12 June 2014

\section{References}

1. Maulik PK, Mascarenhas MN, Mathers CD, Dua T, Saxena S: Prevalence of intellectual disability: a meta-analysis of population-based studies. Res Dev Disabil 2011, 32(2):419-436.

2. The Disabled Population by Classification and Grade. http://www.mohw.gov. tw/cht/DOS/Statistic.aspx?f_list_no=312\&fod_list_no=4182.

3. Wang YT: Are adults with intellectual disabilities socially excluded? An exploratory study in Taiwan. J Intellect Disabil Res 2013, 57(10):893-902.

4. Durvasula S, Beange $H$, Baker W: Mortality of people with intellectual disability in northern Sydney. J Intellect Dev Disabil 2002, 27(4):255-264.

5. Patja $K$, livanainen $M$, Vesala $H$, Oksanen $H$, Ruoppila I: Life expectancy of people with intellectual disability: a 35-year follow-up study. I Intellect Disabil Res 2000, 44(Pt 5):591-599.

6. Tyrer F, McGrother C: Cause-specific mortality and death certificate reporting in adults with moderate to profound intellectual disability. J Intellect Disabil Res 2009, 53(11):898-904.

7. van Schrojenstein Lantman-De HM, Metsemakers JF, Haveman MJ, Crebolder HF: Health problems in people with intellectual disability in general practice: a comparative study. Fam Pract 2000, 17(5):405-407.

8. Kwok H, Cheung PWH: Co-morbidity of psychiatric disorder and medical illness in people with intellectual disabilities. Curr Opin Psychiatry 2007, 20(5):443-449.

9. Lin JD, Yen CF, Loh CH, Hsu SW, Huang HC, Tang CC, Li CW, Wu JL: A cross-sectional study of the characteristics and determinants of emergency care utilization among people with intellectual disabilities in Taiwan. Res Dev Disabil 2006, 27(6):657-667.

10. Rimmer JH, Yamaki K, Lowry BMD, Wang E, Vogel LC: Obesity and obesity-related secondary conditions in adolescents with intellectual/ developmental disabilities. J Intellect Disabil Res 2010, 54(9):787-794.

11. Sohler N, Lubetkin E, Levy J, Soghomonian C, Rimmerman A: Factors associated with obesity and coronary heart disease in people with intellectual disabilities. Soc Work Health Care 2009, 48(1):76-89.

12. Diab ME, Johnston MV: Relationships between level of disability and receipt of preventive health services. Arch Phys Med Rehabil 2004, 85(5):749-757.

13. Lin JD, Yen $C F, W u J L$ : Importance and satisfaction of preventive health strategies in institutions for people with intellectual disabilities: a perspective of institutional directors. Res Dev Disabil 2005, 26(3):267-280.

14. Weng RH, Kung PT, Tsai WC, Chiang HH, Chiu LT: The use of fluoride varnish and its determining factors among children with disability in Taiwan. Res Dev Disabil 2011, 32(2):583-592.

15. lezzoni LI, McCarthy EP, Davis RB, Harris-David L, O'Day B: Use of screening and preventive services among women with disabilities. Am J Med Qual 2001, 16(4):135-144.

16. Phillips KA, Mayer ML, Aday LA: Barriers to care among racial/ethnic groups under managed care. Health Aff 2000, 19(4):65-75.

17. Ramirez A, Farmer GC, Grant D, Papachristou T: Disability and preventive cancer screening: results from the 2001 California Health Interview Survey. Am J Public Health 2005, 95(11):2057-2064.

18. Shabas D, Weinreb H: Preventive healthcare in women with multiple sclerosis. J Womens Health Gend Based Med 2000, 9(4):389-395.

19. Pearson V, Davis C, Ruoff C, Dyer J: Only one quarter of women with learning disability in Exeter have cervical screening. BMJ (Clinical Research Ed) 1998, 316(7149):1979.

20. Perry J, Kerr M, Felce D, Bartley S, Tomlinson J: Monitoring the public health impact of health checks for adults with a learning disability in Wales: Final report of the Public Health Wales WCLD project group. Cardiff: Public Health Wales \& Welsh Centre for Learning Disabilities; 2010. 
21. Lennox N, Bain C, Rey-Conde T, Purdie D, Bush R, Pandeya N: Effects of a comprehensive health assessment programme for Australian adults with intellectual disability: a cluster randomized trial. Int J Epidemiol 2007, 36(1):139-146.

22. Maciosek MV, Coffield AB, Flottemesch TJ, Edwards NM, Solberg LI: Greater use of preventive services in U.S. health care could save lives at little or no cost. Health Aff 2010, 29(9):1656-1660.

23. Gandjour A: Aging diseases-do they prevent preventive health care from saving costs? Health Econ 2009, 18(3):355-362.

24. Macnab AJ, Rozmus J, Benton D, Gagnon FA: 3-year results of a collaborative school-based oral health program in a remote First Nations community. Rural Remote Health 2008, 8(2):882.

25. Malach M, Baumol WJ: Opportunities for the cost reduction of medical care. J Community Health 2009, 34(4):255-261.

26. Rodriguez Vazquez C, Garcillan R, Rioboo R, Bratos E: Prevalence of dental caries in an adult population with mental disabilities in Spain. Spec Care Dentist 2002, 22(2):65-69.

27. Kung PT, Tsai WC, Li YH: Determining factors for utilization of preventive health services among adults with disabilities in Taiwan. Res Dev Disabil 2012, 33(1):205-213.

28. Huang KH, Tsai WC, Kung PT: The use of Pap smear and its influencing factors among women with disabilities in Taiwan. Res Dev Disabil 2012 33(2):307-314.

29. Public Assistance Act. http://law.moj.gov.tw/Eng/LawClass/LawAll.aspx? PCode=D0050078

30. Bertakis KD, Azari R, Helms LJ, Callahan EJ, Robbins JA: Gender differences in the utilization of health care services. J Fam Pract 2000, 49(2):147-152.

31. Green CA, Pope CR: Gender, psychosocial factors and the use of medical services: a longitudinal analysis. Soc Sci Med 1999, 48(10):1363-1372.

32. Owens GM: Gender differences in health care expenditures, resource utilization, and quality of care. J Manag Care Pharm 2008, 14(3 Suppl):2-6.

33. Haveman M, Perry J, Salvador-Carulla L, Walsh PN, Kerr M, Van Schrojenstein Lantman-de Valk H, Van Hove G, Berger DM, Azema B, Buono S, Cara AC, Germanavicius A, Linehan C, Ma"a"tta" T, Tossebro J, Weber G: Ageing and health status in adults with intellectual disabilities: results of the European POMONA II study. J Intellect Dev Disabil 2011, 36(1):49-60.

34. Hewitt M, Devesa SS, Breen N: Cervical cancer screening among U.S women: analyses of the 2000 National Health Interview Survey. Prev Med 2004, 39(2):270-278.

35. Katz SJ, Hofer TP: Socioeconomic disparities in preventive care persist despite universal coverage: breast and cervical cancer screening in Ontario and the United States. JAMA 1994, 272(7):530-534.

36. Rodriguez MA, Ward LM, Perez-Stable EJ: Breast and cervical cancer screening: impact of health insurance status, ethnicity, and nativity of Latinas. Ann Fam Med 2005, 3(3):235-241.

37. Kung PT, Tsai WC, Chiou SJ: The assessment of the likelihood of mammography usage with relevant factors among women with disabilities. Res Dev Disabil 2012, 33(1):136-143.

doi:10.1186/1472-6963-14-248

Cite this article as: Yen et al:: Related factors and use of free preventive health services among adults with intellectual disabilities in Taiwan.

BMC Health Services Research 2014 14:248.

\section{Submit your next manuscript to BioMed Central and take full advantage of:}

- Convenient online submission

- Thorough peer review

- No space constraints or color figure charges

- Immediate publication on acceptance

- Inclusion in PubMed, CAS, Scopus and Google Scholar

- Research which is freely available for redistribution 